\title{
Estimativa da economia governamental advinda do emprego do fator previdenciário
}

\author{
Luiz Henrique Ferreira Cruz e Superti ${ }^{1}$, Helen $\mathrm{Wu}^{1}$, Paloma Soares Novello $\mathrm{Cruz}^{1}$
}

\footnotetext{
${ }^{1}$ Faculdade de Economia, Administração e Contabilidade da Universidade de São Paulo (FEA-USP).

Correspondência: $\quad$ E-mail: luiz.superti@usp.br
}

Resumo O presente trabalho tem como escopo estimar a economia proporcionada pelo emprego do fator previdenciário, introduzido pela Lei 9.876/99. Este tema ganhou notoriedade devido às discussões referentes à extinção do fator no primeiro semestre de 2010, questão originada do Projeto de Lei 3.299/08. A partir de informações do Instituto Brasileiro de Geografia e Estatística (IBGE) e de cruzamentos de dados obtidos do Anuário Estatístico da Previdência Social InfoLogo (AEPS Infologo), foi desenvolvido um exercício empírico contrafactual. Este possibilitou o cálculo da economia obtida pelo governo para as Aposentadorias por Tempo de Contribuição (ATC) concedidas de 2000 até 2009, desde o seu deferimento até a morte de todos os requerentes do período analisado. Verifica-se, como resultado, que o governo gastaria a mais cerca de $\mathbf{R} \$ 10$ bilhões anuais e que a aplicação do fator resultou em economia de mais de $30 \%$ dos gastos totais com as ATCs desse período. A principal conclusão do estudo é que, se o fator previdenciário fosse extinto, o governo teria um dispêndio maior, que possivelmente seria intensificado pelo envelhecimento demográfico brasileiro. Desta forma, percebe-se a relevância do mecanismo para a manutenção do sistema previdenciário do país.

Palavras-chave: previdência social, aposentadoria, gasto de governo.

Abstract The paper presents an estimation of the economy granted by the use of the pension factor, introduced by law 9.876/99. The theme gained attention due to discussions referring to the extinction of the pension factor during the first semester of 2010, proposed in the law project 3.299/08. Using data from Brazilian Institute for Geography and Statistics (IBGE) and Social Security Statistical Yearbook Infologo (AEPS 
InfoLogo), an empirical counterfactual exercise was developed in order to provide information on the economy obtained by the government for pensions based on contribution period (ATC) granted from 2000 until 2009, since approval until death of the beneficiaries of the period analyzed. As result, the government should have spent additional R $\$ 10$ billion per year and the pension factor provided an economy larger than $30 \%$ in government expenditures due to ATCS in the period. The main conclusion is that the extinction of the pension factor would generate a significant increase in government expenditures in social security, which should be deepened by Brazilian demographic aging. Thus, the relevance of the mechanism is stressed in order to maintain the Brazilian social security system.

Keywords: social security, retirement, government expenditures.

Resumen El artículo tiene como objetivo estimar la economía propiciada por el empleo del factor de pensión, introducido pela ley 9.876/99. El tema ganó atención deudo las discusiones de la extinción del factor en el primer semestre de 2010, propuesta por el proyecto de ley 3.299/08. A partir de dados del Instituto Brasileño de Geografía y Estadística (IBGE) y del Anuario Estadístico de la Previdencia Social InfoLogo (AEPS InfoLogo), fue desenvuelto un ejercicio empírico contra factual, que posibilitó el calculo de la economía obtenida por el gobierno por las pensiones por tiempo de contribución (ATC) concedidas del 2000 hasta 2009, desde la aprobación hasta la muerte de los beneficiarios en el periodo estudiado. Verificó-se, como resultado, que el gobierno pasaría más $\mathrm{R} \$ 10$ billones anuales y que la aplicación del factor resulto en una economía de más de $30 \%$ de los gastos totales con las pensiones en el periodo. La principal conclusión del estudio es que si el factor de pensión fuera extinto, el gobierno tendría un desembolso mayor, que posiblemente seria intensificado por el envejecimiento demográfico brasileño. Así, es posible percibir la importancia del mecanismo para la manutención del sistema de seguridad social del país.

Palabras-clave: seguridad social, jubilación, gasto del gobierno. 


\title{
Introdução
}

No Brasil, a Previdência Social é dividida em três regimes: Regimes Geral da Previdência Social (RGPS), Regime Próprio da Previdência Social e Previdência Complementar, respectivamente previstos nos artigos 201, 40 e 202, da Constituição Federal (CF) de 1988. As duas primeiras têm caráter de obrigatoriedade, pois todos os trabalhadores, sendo eles privados ou públicos, precisam contribuir; enquanto que o terceiro regime é facultativo.

Dado o tema do presente trabalho, apenas uma espécie de aposentadoria do RGPS será analisada, a Aposentadoria por Tempo de Contribuição (ATC), segundo Delgado et al. (2006:11):

\begin{abstract}
A Aposentadoria por Tempo de Contribuição (ATC) pode ser integral ou proporcional. Para estarem aptos ao benefício integral, os homens têm de comprovar 35 anos de contribuição e, as mulheres, 30 anos. No caso da ATC proporcional, por sua vez, deve-se combinar dois requisitos: idade mínima e tempo de contribuição. Os homens devem completar 53 anos de idade e 30 anos de contribuição; $e$ as mulheres devem ter pelo menos 48 anos de idade e 25 anos de contribuição.
\end{abstract}

Com a entrada em vigor da lei do fator previdenciário (Lei 9.876/99), em dezembro de 1999, sobre esta aposentadoria, a regra de cálculo dos benefícios do RGPS foi modificada com o intuito de se desestimular a aposentadoria precoce.

Tal medida é relevante diante da conjuntura econômico-demográfica brasileira, pois se observam, concomitantemente, o aumento da expectativa de sobrevida da população e a diminuição da taxa de fertilidade, fatos que podem implicar em um grande desequilíbrio atuarial e financeiro na previdência social.

Entretanto, no primeiro semestre de 2010, discutiu-se sobre a extinção do fator previdenciário, questão originada do Projeto Lei 3.299/08. Desta maneira, é relevante estimar a alteração nos gastos governamentais quando da aplicação ou não do mecanismo em questão, a fim de se evitar o aumento do déficit previdenciário.

Com o intuito de se avaliar quão importante foi a introdução do fator previdenciário, este trabalho estima a economia que o governo obtém ao aplicar o fator às pessoas que requereram a aposentadoria entre 2000 e 2009 até suas mortes, de acordo com a expectativa de sobrevida do Instituto Brasileiro de Geografia e Estatística (IBGE). 
O fator previdenciário é representado pela seguinte fórmula:

\section{Equação 1}

$$
f=\frac{T c \cdot a}{E s} \cdot\left[1+\left(\frac{I d+T c \cdot a}{100}\right)\right]
$$

Em que $f$ representa o fator previdenciário, Es a expectativa de sobrevida do trabalhador na data de aposentadoria, tc o tempo de contribuição do trabalhador, Id a idade do trabalhador na data da aposentadoria e a a alíquota, que corresponde a 0,31 sobre o salário de contribuição, segundo cálculos do IBGE, sendo que $20 \%$ é recolhido pelo empregador e $11 \%$ pelo empregado (Giambiagi e Afonso 2009).

Pode-se notar através desta função que à medida que o Es aumenta, tendência que pode ser vinculada pelas tábuas do IBGE, o fator previdenciário diminui. Adicionalmente, quanto maiores o tempo de contribuição e a idade de aposentadoria, maior é o fator, de forma que o segurado deverá retardar o requerimento do benefício para se amenizar a penalidade pecuniária.

Entretanto, quando da introdução do fator, o Legislativo estipulou um período de transição de 60 meses (de novembro de 1999 a novembro de 2004), cuja fórmula aplicada foi:

\section{Equação 2}

$$
f n=\left(\frac{F . n}{60}\right)+\left(\frac{60-n}{60}\right)
$$

Onde $f n$ representa o fator de transição, $f$ o fator previdenciário (definido anteriormente) e $n$ o número de meses decorridos entre a data de promulgação da lei e a data de aposentadoria do segurado.

Esta regra de transição visou tornar graduais os efeitos da Lei 9.876, ou seja, para aqueles que se aposentaram em dezembro de 1999, o fator previdenciário teve uma incidência mais branda, sendo aumentada paulatinamente até a sua plenitude em final de 2004. 


\section{Metodologia}

Visando-se o desenvolvimento do trabalho, foi realizada uma análise empírica contrafactual a partir de dados de 2000 a 2009 retirados do Anuário Estatístico da Previdência Social InfoLogo (AEPS InfoLogo), disponibilizados no site do Ministério da Previdência Social (MPS).

Após a entrada em vigor da Lei 9.876/99, a ATC se tornou uma contribuição mensal calculada pelo Instituto Nacional do Seguro Social (INSS) multiplicada pelo fator previdenciário, como segue:

\section{Equação 3}

$$
A p L=F \cdot A p B
$$

Em que Fé o fator previdenciário, $A p B$ o valor da aposentadoria "bruta", ou seja, sem a aplicação do fator e $A$ pl, a aposentadoria "líquida", em outros termos, o valor que de fato o aposentado recebe a cada mês, sendo este o apresentado pelo AEPS InfoLogo.

Como o escopo do presente trabalho é estimar o custo adicional ao governo, caso o fator fosse extinto em 2010, o resultado de: $A p B-A p L$ é o valor almejado. Entretanto, como $A p B-A p L / F$, obtém-se: $A p L / F-A p L$, e substituindo $F$ pela fórmula completa do fator previdenciário, tem-se: $A p L /((T c \cdot a) / E s \cdot[1+((I d+$ Tc. a)/100)] ) $-A p L$.

Desta maneira, o custo que o governo teria a mais ao conceder a aposentadorias sem o emprego do fator previdenciário, seria o somatório da equação acima aplicada a todos os indivíduos, que tiveram suas aposentadorias concedidas durante a vigência do fator até as suas mortes:

Equação 4

$$
\text { Custo Adicional }=\sum \frac{A p L}{\frac{T c \cdot a}{E s} \cdot\left[1+\left(\frac{I d+T c \cdot a}{100}\right)\right]}-A p L
$$

Cabe ressaltar que ainda há implicação do fator de transição de novembro de 1999 a novembro de 2004, sendo empregado o mesmo raciocínio para estes, substituindo-se apenas $F$ por $f n$, já definido na introdução: 


\section{Equação 5}

$$
\text { Custo Adicional de Transição }=\sum \frac{\text { ApL }}{\left(\frac{\text { F.n }}{60}\right)+\left(\frac{60-n}{60}\right)}-\text { ApL }
$$

As tabelas a seguir transcrevem os dados obtidos do AEPS InfoLogo, referentes apenas à ATC (integral e proporcional), também conhecida como Aposentadoria por Tempo de Serviço, disciplinada pela Lei 3.807/60 (Lei Orgânica da Previdência Social - LOPS).

Contudo, cabe ressaltar que não foram incluídos no estudo: a aposentadoria especial, pois o número de benefícios concedidos nesta categoria é estatisticamente insignificante; nem o ano de 2009, já que a Lei 9.876/99 somente entrou em vigor em 29 de novembro de 2009; ambos os fatos que resultariam numa distorção da estimativa procurada.

Tabela 1. Quantidade de aposentadorias concedidas, tipo 42 (LOPS) por tempo de contribuição - Homens.

\begin{tabular}{lrrrrrrrrrr}
\hline $\begin{array}{l}\text { Tempo de } \\
\text { Contribuição }\end{array}$ & 2000 & 2001 & 2002 & 2003 & 2004 & 2005 & 2006 & 2007 & 2008 & 2009 \\
\hline 30 anos & 22.898 & 18.460 & 19.064 & 8.447 & 5.691 & 4.058 & 4.108 & 3.480 & 3.327 & 2.654 \\
\hline 31 anos & 13.869 & 14.176 & 22.872 & 17.526 & 15.561 & 11.670 & 7.777 & 6.436 & 5.354 & 4.626 \\
\hline 32 anos & 9.919 & 9.314 & 13.718 & 11.887 & 11.956 & 13.002 & 16.900 & 19.376 & 17.645 & 13.983 \\
\hline 33 anos & 6.991 & 5.762 & 9.592 & 8.892 & 9.001 & 8.879 & 10.415 & 13.274 & 14.737 & 19.544 \\
\hline 34 anos & 4.597 & 4.209 & 6.454 & 6.276 & 6.458 & 6.136 & 7.078 & 8.207 & 8.485 & 10.002 \\
\hline 35 anos & 10.414 & 11.275 & 20.168 & 20.598 & 28.522 & 35.323 & 44.388 & 62.813 & 74.213 & 83.215 \\
\hline 36 anos & 4.527 & 4.537 & 7.520 & 6.617 & 7.371 & 8.492 & 11.624 & 16.498 & 19.532 & 22.039 \\
\hline 37 anos & 2.450 & 2.388 & 3.938 & 3.424 & 3.807 & 4.273 & 5.905 & 9.127 & 11.264 & 12.409 \\
\hline 38 anos & 1.364 & 1.353 & 2.241 & 1.874 & 2.213 & 2.390 & 3.247 & 5.112 & 6.894 & 7.806 \\
\hline 39 anos & 805 & 791 & 1.332 & 1.053 & 1.272 & 1.460 & 1.924 & 2.938 & 4.128 & 4.930 \\
\hline 40 anos ou mais & 1.451 & 1.327 & 1.963 & 1.591 & 1.941 & 2.479 & 3.185 & 4.708 & 5.984 & 7.261 \\
\hline Ignorado & 410 & 2.284 & 500 & 873 & 1.186 & 1.003 & 1.717 & 2.137 & 1.919 & 1.487 \\
\hline Total & 79.695 & 75.876109 .362 & 89.058 & 94.979 & 99.165118 .268154 .106173 .482189 .956 \\
\hline
\end{tabular}

Fonte: AEPS InfoLogo. 
Tabela 2. Quantidade de aposentadorias concedidas, tipo 42 (LOPS) por tempo de contribuição - Mulheres.

\begin{tabular}{lrrrrrrrrrr}
\hline $\begin{array}{l}\text { Tempo de } \\
\text { Contribuição }\end{array}$ & 2000 & 2001 & 2002 & 2003 & 2004 & 2005 & 2006 & 2007 & 2008 & 2009 \\
\hline 25 anos & 11.532 & 8.606 & 6.055 & 2.033 & 1.367 & 1.002 & 970 & 878 & 764 & 575 \\
\hline 26 anos & 5.781 & 6.846 & 13.143 & 12.351 & 11.250 & 7.937 & 4.203 & 3.207 & 2.441 & 2.124 \\
\hline 27 anos & 3.394 & 4.043 & 6.464 & 6.897 & 6.818 & 8.150 & 11.780 & 14.265 & 12.860 & 9.549 \\
\hline 28 anos & 2.193 & 2.228 & 4.351 & 5.345 & 5.163 & 4.850 & 5.892 & 8.074 & 8.850 & 12.658 \\
\hline 29 anos & 1.556 & 1.686 & 2.564 & 3.412 & 3.481 & 3.384 & 3.916 & 4.840 & 5.076 & 5.779 \\
\hline 30 anos & 4.126 & 4.837 & 8.028 & 10.015 & 15.478 & 19.518 & 24.858 & 36.416 & 39.580 & 40.619 \\
\hline 31 anos & 1.390 & 1.411 & 2.292 & 2.202 & 2.490 & 3.266 & 4.869 & 7.943 & 7.775 & 7.973 \\
\hline 32 anos & 786 & 833 & 1.299 & 1.098 & 1.129 & 1.367 & 2.083 & 4.169 & 4.143 & 4.106 \\
\hline 33 anos & 525 & 503 & 729 & 563 & 629 & 749 & 1.060 & 2.075 & 2.359 & 2.335 \\
\hline 34 anos & 263 & 330 & 396 & 293 & 321 & 411 & 581 & 1.090 & 1.236 & 1.351 \\
\hline 35 anos & 153 & 212 & 299 & 234 & 226 & 268 & 441 & 703 & 769 & 951 \\
\hline 36 anos & 114 & 95 & 158 & 151 & 138 & 155 & 261 & 372 & 412 & 476 \\
\hline 37 anos & 68 & 67 & 82 & 68 & 80 & 97 & 156 & 277 & 241 & 285 \\
\hline 38 anos & 45 & 42 & 44 & 52 & 52 & 65 & 100 & 148 & 165 & 199 \\
\hline 39 anos & 30 & 39 & 23 & 19 & 30 & 42 & 71 & 93 & 110 & 123 \\
\hline 40 anos ou mais & 71 & 69 & 63 & 59 & 71 & 90 & 123 & 182 & 196 & 246 \\
\hline Ignorado & 101 & 429 & 93 & 153 & 232 & 211 & 319 & 425 & 395 & 331 \\
\hline Total & 32.128 & 32.276 & 46.083 & 44.945 & 48.955 & 51.562 & 61.683 & 85.157 & 87.372 & 89.680 \\
\hline
\end{tabular}

Fonte: AEPS InfoLogo.

Tabela 3. Quantidade de aposentadorias concedidas, tipo 42 (LOPS) por Idade Homens.

\begin{tabular}{lrrrrrrrrrr}
\hline Idade & 2000 & 2001 & 2002 & 2003 & 2004 & 2005 & 2006 & 2007 & 2008 & 2009 \\
\hline 30 a 34 anos & 9 & 2 & 5 & 3 & 1 & 2 & 2 & 1 & 2 & 0 \\
\hline 35 a 39 anos & 1.055 & 696 & 557 & 359 & 307 & 340 & 380 & 406 & 557 & 0 \\
\hline 40 a 44 anos & 8.478 & 6.387 & 6.050 & 2.980 & 2.836 & 3.023 & 3.563 & 3.892 & 5.022 & 3.975 \\
\hline 45 a 49 anos & 15.716 & 14.972 & 16.706 & 9.783 & 10.174 & 10.561 & 13.209 & 16.546 & 21.459 & 21.853 \\
\hline 50 a 54 anos & 22.623 & 23.381 & 36.397 & 33.129 & 36.166 & 37.958 & 45.157 & 59.440 & 66.383 & 73.300 \\
\hline 55 a 59 anos & 19.853 & 19.316 & 32.160 & 28.379 & 30.061 & 32.085 & 38.842 & 52.291 & 57.142 & 63.733 \\
\hline 60 a 64 anos & 10.761 & 9.931 & 15.611 & 13.302 & 14.421 & 14.224 & 16.217 & 20.457 & 22.010 & 25.681 \\
\hline 65 a 69 anos & 1.024 & 991 & 1.580 & 950 & 879 & 825 & 769 & 899 & 788 & 911 \\
\hline 70 a 74 anos & 139 & 149 & 165 & 127 & 106 & 116 & 98 & 124 & 84 & 111 \\
\hline 75 a 79 anos & 26 & 20 & 42 & 30 & 23 & 21 & 17 & 41 & 26 & 28 \\
\hline 80 a 84 anos & 9 & 11 & 11 & 7 & 2 & 7 & 7 & 3 & 5 & 7 \\
\hline 85 a 89 anos & 1 & 2 & 8 & 5 & 1 & 1 & 3 & 2 & 2 & 3 \\
\hline 90 anos ou mais & 0 & 16 & 69 & 4 & 1 & 1 & 3 & 4 & 2 & 1 \\
\hline Ignorada & 1 & 2 & 1 & 0 & 1 & 1 & 1 & 0 & 0 & 2
\end{tabular}

Total $\quad 79.69575 .876109 .36289 .05894 .97999 .165118 .268154 .106173 .482189 .605$

Fonte: AEPS InfoLogo. 
Tabela 4. Quantidade de aposentadorias concedidas, tipo 42 (LOPS) por Idade Mulheres.

\begin{tabular}{lrrrrrrrrrr}
\hline Idade & 2000 & 2001 & 2002 & 2003 & 2004 & 2005 & 2006 & 2007 & 2008 & 2009 \\
\hline 30 a 34 anos & 1 & 2 & 0 & 0 & 1 & 3 & 2 & 3 & 2 & 3 \\
\hline 35 a 39 anos & 511 & 253 & 176 & 88 & 78 & 87 & 139 & 120 & 183 & 116 \\
\hline 40 a 44 anos & 3.468 & 2.455 & 2.145 & 1.044 & 851 & 1.100 & 1.477 & 1.890 & 2.710 & 2.776 \\
\hline 45 a 49 anos & 9.987 & 10.998 & 15.156 & 16.140 & 17.830 & 18.808 & 21.412 & 28.343 & 28.013 & 27.202 \\
\hline 50 a 54 anos & 10.769 & 11.334 & 17.093 & 16.456 & 17.702 & 19.086 & 23.988 & 35.371 & 36.089 & 37.509 \\
\hline 55 a 59 anos & 6.547 & 6.398 & 10.240 & 10.128 & 11.406 & 11.503 & 13.647 & 18.269 & 19.368 & 20.828 \\
\hline 60 a 64 anos & 689 & 682 & 1.021 & 874 & 894 & 808 & 850 & 959 & 831 & 1.030 \\
\hline 65 a 69 anos & 107 & 111 & 162 & 165 & 153 & 132 & 129 & 148 & 128 & 166 \\
\hline 70 a 74 anos & 34 & 24 & 34 & 34 & 20 & 24 & 28 & 40 & 38 & 38 \\
\hline 75 a 79 anos & 9 & 5 & 15 & 9 & 14 & 9 & 8 & 11 & 6 & 7 \\
\hline 80 a 84 anos & 4 & 4 & 1 & 3 & 4 & 1 & 2 & 0 & 2 & 3 \\
\hline 85 a 89 anos & 0 & 2 & 2 & 3 & 1 & 0 & 0 & 1 & 0 & 1 \\
\hline 90 anos ou mais & 1 & 7 & 38 & 1 & 0 & 1 & 1 & 2 & 0 & 0 \\
\hline Ignorada & 1 & 1 & 0 & 0 & 1 & 0 & 0 & 0 & 2 & 1 \\
\hline
\end{tabular}

Total

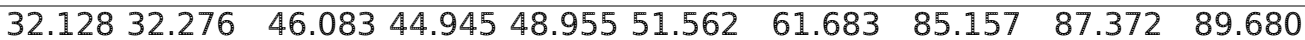

Fonte: AEPS InfoLogo.

Tabela 5. Quantidade de aposentadorias concedidas, tipo 42 (LOPS) por faixas de salário mínimo - Ambos os sexos.

\begin{tabular}{lrrrrrrrrrr}
\hline Faixa & 2000 & 2001 & 2002 & 2003 & 2004 & 2005 & 2006 & 2007 & 2008 & 2009 \\
\hline Igual a 1 & 10.053 & 10.520 & 16.722 & 16.108 & 19.453 & 22.065 & 30.509 & 41.148 & 47.865 & 57.845 \\
\hline De 1 até 2 & 14.174 & 14.431 & 24.686 & 21.741 & 25.544 & 28.745 & 37.729 & 51.053 & 59.032 & 67.819 \\
\hline De 2 até 3 & 15.549 & 15.621 & 25.700 & 22.156 & 24.464 & 27.021 & 33.686 & 45.045 & 49.236 & 54.763 \\
\hline De 3 até 4 & 13.194 & 13.056 & 21.122 & 17.954 & 21.208 & 23.950 & 29.322 & 39.375 & 43.362 & 47.406 \\
\hline De 4 até 5 & 10.766 & 11.437 & 19.145 & 17.594 & 18.767 & 21.346 & 25.683 & 36.646 & 37.941 & 35.140 \\
\hline De 5 até 6 & 12.429 & 15.685 & 21.246 & 16.722 & 16.102 & 15.772 & 14.359 & 17.399 & 16.044 & 11.591 \\
\hline De 6 até 7 & 17.020 & 13.083 & 13.029 & 11.734 & 11.371 & 7.172 & 5.427 & 5.512 & 4.917 & 3.894 \\
\hline De 7 até 8 & 8.188 & 9.737 & 12.810 & 9.602 & 5.193 & 3.050 & 2.181 & 2.349 & 2.041 & 913 \\
\hline De 8 até 9 & 7.457 & 4.385 & 873 & 337 & 1.240 & 1.239 & 970 & 655 & 356 & 223 \\
\hline De 9 até 10 & 2.992 & 195 & 109 & 54 & 591 & 367 & 81 & 73 & 58 & 40 \\
\hline De 10 até 20 & 0 & 2 & 2 & 1 & 1 & 0 & 4 & 8 & 2 & 2 \\
\hline De 20 até 50 & 1 & 0 & 0 & 0 & 0 & 0 & 0 & 0 & 0 & 0 \\
\hline Acima de 50 & 0 & 0 & 1 & 0 & 0 & 0 & 0 & 0 & 0 & 0 \\
\hline
\end{tabular}

Total $\quad 111.823108 .152155 .445134 .003143 .934150 .727179 .951239 .263260 .854279 .636$

Fonte: AEPS InfoLogo.

Tabela 6. Distribuição mensal das aposentadorias concedidas, tipo 42 (LOPS).

\begin{tabular}{lrrrrrrrrrr}
\hline Mês & 2000 & 2001 & 2002 & 2003 & 2004 & 2005 & 2006 & 2007 & 2008 & 2009 \\
\hline Janeiro & 9.081 & 7.207 & 10.648 & 9.913 & 8.865 & 10.040 & 10.960 & 14.547 & 17.863 & 19.388 \\
\hline Fevereiro & 7.474 & 6.842 & 10.953 & 11.305 & 8.472 & 9.905 & 12.009 & 13.855 & 17.703 & 20.471 \\
\hline Março & 10.453 & 10.100 & 13.546 & 10.490 & 12.595 & 15.010 & 15.010 & 19.793 & 21.131 & 27.985 \\
\hline Abril & 11.077 & 10.095 & 14.408 & 12.033 & 11.599 & 14.352 & 12.846 & 18.403 & 22.537 & 26.333 \\
\hline Maio & 11.359 & 13.175 & 14.736 & 14.517 & 9.380 & 15.396 & 16.499 & 21.500 & 21.788 & 25.015 \\
\hline Junho & 8.928 & 13.127 & 12.901 & 12.102 & 12.331 & 10.841 & 14.613 & 19.836 & 22.953 & 25.305 \\
Julho & 7.623 & 13.014 & 12.753 & 9.138 & 13.631 & 8.056 & 14.918 & 19.477 & 21.131 & 23.480 \\
\hline Agosto & 9.476 & 9.136 & 13.244 & 6.191 & 15.311 & 11.565 & 18.597 & 25.751 & 23.160 & 24.875 \\
\hline Setembro & 8.633 & 4.592 & 13.025 & 11.343 & 14.756 & 15.431 & 15.626 & 21.517 & 24.639 & 23.465 \\
\hline Outubro & 9.871 & 4.577 & 15.074 & 13.303 & 12.937 & 13.166 & 16.926 & 23.719 & 24.274 & 23.114 \\
\hline Novembro & 9.008 & 5.368 & 12.493 & 11.879 & 12.632 & 13.733 & 16.187 & 21.542 & 22.402 & 21.036 \\
\hline Dezembro & 8.840 & 10.919 & 11.664 & 11.789 & 11.425 & 13.232 & 15.760 & 19.323 & 21.273 & 19.169 \\
\hline Total & 111.823 & 108.152 & 155.445 & 134.003 & 143.934 & 150.727 & 179.951 & 239.263 & 260.854 & 279.636 \\
\hline
\end{tabular}


As Tabelas 1 e 2 informam, respectivamente, a quantidade de aposentadorias concedidas para homens e para mulheres, desde 2000 até 2009, de acordo com o tempo de contribuição (TC).

Da mesma forma, pode-se verificar nas Tabelas 3 e 4, a quantidade de aposentadorias concedidas no mesmo período, conforme a faixa de idade (/d) e indiretamente segundo a expectativa de sobrevida (ES); enquanto a Tabela 5 apresenta o número de benefícios concedidos para ambos os sexos consoante a ApL, ou seja, de acordo com o valor da aposentadoria dividida por faixas de salário mínimo, cujo valor diverge entre os anos, devido aos reajustes aprovados por lei.

Por último, a Tabela 6 mostra o número de aposentadorias de ambos os sexos concedidas desde 2000 a 2009 dividido pelos meses, sendo útil para analisar a influência do fator previdenciário durante o período de transição (novembro de 1999 a novembro de 2004).

Para a viabilização do trabalho, em outros termos, para se utilizar a equação custo adicional e a equação custo adicional de transição, percebe-se que é necessário cruzar os dados das tabelas acima.

Por exemplo, é preciso saber quantos homens de 60 anos se aposentaram com tempo de contribuição de 30 anos e recebendo exatamente $R \$ 650,00$ (seiscentos e cinquenta reais).

Entretanto, com os dados disponibilizados pelo AEPS InfoLogo, apenas é possível identificar quantas pessoas do sexo masculino se aposentaram com $T c=30$ ou o número de benefícios deferidos quando o indivíduo tinha $\mathbb{l} d=60$, já que as informações estão tabuladas separadamente.

Adicionalmente, como os dados das Tabelas 1, 2 e 5 estão apresentados em intervalos, é preciso definir um ponto médio a cada um deles, possibilitando o cruzamento das informações.

Em relação às Tabelas 3 e 4, substituem-se os intervalos de idade pela média de cada grupo etário; exempli gratia: em 2009, ao invés de considerar que 25.681 homens se aposentaram com idade entre 60 e 64 anos, adota-se 62 anos.

Semelhantemente, para utilizar a Tabela 5, que se refere às faixas de salário mínimo, ao invés de considerar que, em 2009, 11.591 aposentadorias concedidas eram entre 5 e 6 salários mínimos, emprega-se 5,5.

É importante ressaltar que a substituição de cada intervalo pelo seu respectivo ponto médio é uma medida razoável. Multiplicando o ponto médio das faixas de salário mínimo pela menor remuneração legalmente permitida de cada ano e pelas quantidades de ATCs concedidas no intervalo, constrói-se a Tabela 8. 
Ao comparar esta com o real valor total das aposentadorias concedidas (Tabela 7), percebe-se que, em termos monetários, o viés é pequeno (máximo de 5,4\%, em 2005) e sempre positivo.

Tabela 7. Valor total das aposentadorias concedidas (em R\$ Milhões).

\begin{tabular}{cccccccccc}
\hline 2000 & 2001 & 2002 & 2003 & 2004 & 2005 & 2006 & 2007 & 2008 & 2009 \\
\hline 72,73 & 77,85 & 113,74 & 112,20 & 125,40 & 137,47 & 178,35 & 255,37 & 293,67 & 329,04 \\
\hline
\end{tabular}

Fonte: AEPS InfoLogo.

Tabela 8. Valor total das aposentadorias concedidas (em milhões de reais), utilizando o ponto médio (PM) das faixas de salário mínimo como referência.

\begin{tabular}{lrrrrrrrrrr} 
PM & 2000 & 2001 & 2002 & 2003 & 2004 & 2005 & 2006 & 2007 & 2008 & 2009 \\
\hline 1 & 1,52 & 1,89 & 3,34 & 3,87 & 5,06 & 6,62 & 10,68 & 15,64 & 19,86 & 26,90 \\
\hline 1,5 & 3,21 & 3,90 & 7,41 & 7,83 & 9,96 & 12,94 & 19,81 & 29,10 & 36,75 & 47,30 \\
\hline 2,5 & 5,87 & 7,03 & 12,85 & 13,29 & 15,90 & 20,27 & 29,48 & 42,79 & 51,08 & 63,66 \\
\hline 3,5 & 6,97 & 8,23 & 14,79 & 15,08 & 19,30 & 25,15 & 35,92 & 52,37 & 62,98 & 77,15 \\
\hline 4,5 & 7,32 & 9,26 & 17,23 & 19,00 & 21,96 & 28,82 & 40,45 & 62,66 & 70,85 & 73,53 \\
\hline 5,5 & 10,32 & 15,53 & 23,37 & 22,07 & 23,03 & 26,02 & 27,64 & 36,36 & 36,62 & 29,64 \\
\hline 6,5 & 16,71 & 15,31 & 16,94 & 18,31 & 19,22 & 13,99 & 12,35 & 13,61 & 13,26 & 11,77 \\
\hline 7,5 & 9,27 & 13,14 & 19,22 & 17,28 & 10,13 & 6,86 & 5,73 & 6,69 & 6,35 & 3,18 \\
\hline 8,5 & 9,57 & 6,71 & 1,48 & 0,69 & 2,74 & 3,16 & 2,89 & 2,12 & 1,26 & 0,88 \\
\hline 9,5 & 4,29 & 0,33 & 0,21 & 0,12 & 1,46 & 1,05 & 0,27 & 0,26 & 0,23 & 0,18 \\
\hline 15 & 0,00 & 0,01 & 0,01 & 0,00 & 0,00 & 0,00 & 0,02 & 0,05 & 0,01 & 0,01 \\
\hline 35 & 0,01 & 0,00 & 0,00 & 0,00 & 0,00 & 0,00 & 0,00 & 0,00 & 0,00 & 0,00 \\
\hline 50 & 0,00 & 0,00 & 0,01 & 0,00 & 0,00 & 0,00 & 0,00 & 0,00 & 0,00 & 0,00 \\
\hline Total & 75,06 & 81,34 & 116,85 & 117,55 & 128,75 & 144,86 & 185,22 & 261,66 & 299,27 & 334,22 \\
\hline
\end{tabular}

Fonte: elaboração dos autores a partir de dados de AEPS InfoLogo.

Após estes procedimentos, pode-se, enfim, cruzar as tabelas. Visando explicar detalhadamente este método, usam-se como exemplo os dados de 2009.

Para definir a quantidade de pessoas que se aposentaram a certa idade, com determinada renda e exato tempo de contribuição, encontra-se primeiramente a proporção destes itens em sua respectiva tabela, atribuindo variáveis a cada uma, entre os parênteses. 
Tabela 9. ATCs concedidas em 2009 e suas proporções, segundo tempo de contribuição - Homens.

\begin{tabular}{lcc}
\hline Tempo de Contribuição $(\mathrm{J})$ & ATC Concedidas & Proporção sobre o total \\
\hline 30 Anos ( $=30)$ & 2.654 & $1,40 \%$ \\
\hline 31 Anos (31) & 4.626 & $2,44 \%$ \\
\hline 32 Anos (32) & 13.983 & $7,36 \%$ \\
\hline 33 Anos (33) & 19.544 & $10,29 \%$ \\
\hline 34 Anos (34) & 10.002 & $5,27 \%$ \\
\hline 35 Anos (35) & 83.215 & $43,81 \%$ \\
\hline 36 Anos (36) & 22.039 & $11,60 \%$ \\
\hline 37 Anos (37) & 12.409 & $6,53 \%$ \\
\hline 38 Anos (38) & 7.806 & $4,11 \%$ \\
\hline 40 Anos (39) & 4.930 & $2,60 \%$ \\
\hline Ignorado ou mais (40) & 7.261 & $3,82 \%$ \\
\hline Total & 1.487 & $0,78 \%$ \\
\hline Ton & 189.956 & $100,00 \%$
\end{tabular}

Fonte: elaboração dos autores a partir de dados de AEPS InfoLogo.

Tabela 10. ATCs concedidas em 2009 e suas proporções, segundo idade média (Homens).

\begin{tabular}{|c|c|c|}
\hline Idade Média (I) & ATC Concedidas & Proporção sobre o total \\
\hline $32 \operatorname{Anos}(i=1)$ & 0 & $0,00 \%$ \\
\hline 37 Anos (2) & 351 & $0,18 \%$ \\
\hline 42 Anos (3) & 3.975 & $2,09 \%$ \\
\hline 47 Anos (4) & 21.853 & $11,50 \%$ \\
\hline 52 Anos (5) & 73.300 & $38,59 \%$ \\
\hline 57 Anos (6) & 63.733 & $33,55 \%$ \\
\hline 62 Anos (7) & 25.681 & $13,52 \%$ \\
\hline 67 Anos (8) & 911 & $0,48 \%$ \\
\hline 72 Anos (9) & 111 & $0,06 \%$ \\
\hline 77 Anos (10) & 28 & $0,01 \%$ \\
\hline 82 Anos (11) & 7 & $0,00 \%$ \\
\hline 87 Anos (12) & 3 & $0,00 \%$ \\
\hline 90 Anos (13) & 1 & $0,00 \%$ \\
\hline Ignorada & 2 & $0,00 \%$ \\
\hline Total & 189.956 & $100,00 \%$ \\
\hline
\end{tabular}

Fonte: elaboração dos autores a partir de dados de AEPS InfoLogo. 
Tabela 11. Distribuição mensal das ATCs em 2009 e suas proporções (ambos os sexos).

\begin{tabular}{lcc}
\hline Mês $(M)$ & ATCs Concedidas & Proporção sobre o total \\
\hline Janeiro $(m=1)$ & 19.388 & $6,93 \%$ \\
\hline Fevereiro (2) & 20.471 & $7,32 \%$ \\
\hline Março (3) & 27.985 & $10,01 \%$ \\
\hline Abril (4) & 26.333 & $9,42 \%$ \\
\hline Maio (5) & 25.015 & $8,95 \%$ \\
\hline Junho (6) & 25.305 & $9,05 \%$ \\
\hline Julho (7) & 23.480 & $8,40 \%$ \\
\hline Agosto (8) & 24.875 & $8,90 \%$ \\
\hline Setembro (9) & 23.465 & $8,39 \%$ \\
\hline Outubro (10) & 23.114 & $8,27 \%$ \\
\hline Novembro (11) & 21.036 & $7,52 \%$ \\
\hline Dezembro (12) & 19.169 & $6,85 \%$ \\
\hline Total & 279.636 & $100,00 \%$ \\
\hline
\end{tabular}

Fonte: elaboração dos autores a partir de dados de AEPS InfoLogo.

Tabela 12. ATCs Concedidas em 2009 e suas proporções, segundo faixa salarial (ambos os sexos).

\begin{tabular}{lcc}
\hline Faixa Salarial - Em Pisos $(P)$ & ATC Concedidas & Proporção sobre o total \\
\hline $1(p=1)$ & 57.845 & $20,69 \%$ \\
\hline $1,5(2)$ & 67.819 & $24,25 \%$ \\
\hline $2,5(3)$ & 54.763 & $19,58 \%$ \\
\hline $3,5(4)$ & 47.406 & $16,95 \%$ \\
\hline $4,5(5)$ & 35.140 & $12,57 \%$ \\
\hline $5,5(6)$ & 11.591 & $4,15 \%$ \\
\hline $6,5(7)$ & 3.894 & $1,39 \%$ \\
\hline $7,5(8)$ & 913 & $0,33 \%$ \\
\hline $8,5(9)$ & 223 & $0,08 \%$ \\
\hline $9,5(10)$ & 40 & $0,01 \%$ \\
\hline $15(11)$ & 2 & $0,00 \%$ \\
\hline $35(12)$ & 0 & $0,00 \%$ \\
\hline $50(13)$ & 0 & $0,00 \%$ \\
\hline Total & 279.636 & $100,00 \%$ \\
\hline Fon & &
\end{tabular}

Fonte: elaboração dos autores a partir de dados de AEPS InfoLogo.

Em seguida, multiplicam-se as quantidades de ATCs concedidas da Tabela 9, pelas proporções encontradas nas outras três tabelas. Quer dizer, isso implica na seguinte suposição, de que a distribuição da estatística Idade segue a mesma distribuição (neste caso, da distribuição geral, da Tabela 10) em cada subgrupo da Tabela 9.

Bem como a estatística da Tabela 11, de distribuição mensal: A distribuição mensal das ATCs segue a mesma distribuição da Tabela 11 (distribuição do total das aposentadorias), em cada subgrupo da Tabela 10, que por sua vez, tem sua distribuição baseada no total das aposentadorias, como descrito anteriormente. O raciocínio é aplicado até a última tabela necessária, Tabela 12. 
Como exemplo de combinação, pode-se citar: das 2.654 pessoas que se aposentaram com 30 anos de contribuição (Tabela 9), 13,52\% possuem de 60 a 64 anos (Tabela 10). Destes, 7,32\% se aposentaram em fevereiro (Tabela 11), e, dos últimos, $24,25 \%$ se aposentaram com 1,5 salários mínimos (Tabela 12). Assim, têm-se que aproximadamente 0,003\% dos homens que se aposentaram em 2009 ( 6 homens), se aposentaram com essas características.

Todavia, tal suposição pode implicar em conflito: ao cruzar os dados, supõe-se a mesma proporção de aposentados com tempo de contribuição de 30 anos tanto para pessoas que se aposentaram entre 30 e 34 anos, quanto para aquelas que começaram a receber o benefício entre 60 e 64 anos.

Na realidade, tal fato não acontece, pois se sabe que há maior proporção de jovens aposentados com menor tempo de contribuição do que pessoas mais idosas. Entretanto, este problema pode ser razoavelmente solucionado, já que são utilizadas todas as estratificações possíveis.

Como a maioria dos grupos das tabelas é empregada, o viés causado em um grupo pode ser amenizado por outro, pois, ao final dos cálculos, estima-se o custo baseado na média do total das ATCS concedidas no ano. Se o objetivo fosse determinar a economia relativa a apenas um grupo de idade, o resultado obtido não seria confiável. Ao final dos cruzamentos, chega-se a uma infinidade de tabelas. Para efeito de ilustração, tem-se como exemplo a Tabela 13.

Tabela 13. Quantidade de ATCs concedidas em fevereiro $(m=2)$ de 2009 a homens de 60 a 64 anos, segundo tempo de contribuição e faixas de valor (Valores arredondados).

\begin{tabular}{|c|c|c|c|c|c|c|c|c|c|c|}
\hline & & & & & Grupo E & ário: 62 ( & =7) & & & \\
\hline & & & & & Faix & Salarial & & & & \\
\hline Tempo de & 465,0 & 697,5 & 1.162, & $1.627,5$ & $2.092,5$ & $2.557,5$ & $3.022,5$ & $3.487,5$ & $3.952,5$ & $4.417,5$ \\
\hline $\begin{array}{l}\text { Contribuiç } \\
\text { ão (J) }\end{array}$ & $\begin{array}{c}0 \\
(p=1)\end{array}$ & $\begin{array}{c}0 \\
(p=2)\end{array}$ & $\begin{array}{c}5 \\
(p=3)\end{array}$ & $\begin{array}{c}0 \\
(p=4)\end{array}$ & $\begin{array}{c}0 \\
(p=5)\end{array}$ & $\begin{array}{c}0 \\
(p=6)\end{array}$ & $\begin{array}{c}0 \\
(p=7)\end{array}$ & $\begin{array}{c}0 \\
(p=8)\end{array}$ & $\begin{array}{c}0 \\
(p=9)\end{array}$ & $\begin{array}{c}0 \\
(p=10)\end{array}$ \\
\hline 30 Anos & 5 & 6 & 5 & 4 & 3 & 1 & 0 & 0 & 0 & 0 \\
\hline 31 Anos & 9 & 11 & 9 & 8 & 6 & 2 & 1 & 0 & 0 & 0 \\
\hline 32 Anos & 29 & 34 & 27 & 24 & 17 & 6 & 2 & 0 & 0 & 0 \\
\hline 33 Anos & 40 & 47 & 38 & 33 & 24 & 8 & 3 & 1 & 0 & 0 \\
\hline 34 Anos & 21 & 24 & 19 & 17 & 12 & 4 & 1 & 0 & 0 & 0 \\
\hline 35 Anos & 171 & 200 & 162 & 140 & 104 & 34 & 11 & 3 & 1 & 0 \\
\hline 36 Anos & 45 & 53 & 43 & 37 & 27 & 9 & 3 & 1 & 0 & 0 \\
\hline 37 Anos & 25 & 30 & 24 & 21 & 15 & 5 & 2 & 0 & 0 & 0 \\
\hline 38 Anos & 16 & 19 & 15 & 13 & 10 & 3 & 1 & 0 & 0 & 0 \\
\hline 39 Anos & 10 & 12 & 10 & 8 & 6 & 2 & 1 & 0 & 0 & 0 \\
\hline $\begin{array}{l}40 \text { Anos } \\
\text { ou mais }\end{array}$ & 15 & 17 & 14 & 12 & 9 & 3 & 1 & 0 & 0 & 0 \\
\hline Total & 387 & 453 & 366 & 317 & 235 & 77 & 26 & 6 & 1 & 0 \\
\hline
\end{tabular}

Fonte: elaboração dos autores a partir de dados de AEPS InfoLogo. 
Por esta tabela, pode ser visto que seis pessoas, de 60 a 64 anos (média de 62 anos), com tempo de contribuição de 30 anos, recebem uma aposentadoria equivalente a um valor entre 1 e 2 salários mínimos (média de 1,5 que, em fevereiro de 2009, corresponde a R $\$ 697,50$ ), como descrito antes.

A partir da reformulação destes dados, as variáveis podem ser empregadas de forma adequada nas duas equações de custo (custo adicional e de custo adicional de transição). Dessa forma, dada a quantidade de ATCs segundo o tempo de contribuição $j$, multiplicada pelas proporções de $i, m$ e $p$, calcula-se o valor que o governo gastará para o grupo escolhido. Isso só se tornou possível, porque os componentes da equação fator previdenciário foram aproximados por meio da extração de $/ d, T C, A p L$ e Es a partir de $i, j, m$ e $p$; utilizados em:

\section{Equação 5}

$$
\text { Custo Adicional }=\sum_{\mathrm{i}=1}^{10} \sum_{\mathrm{j}=30}^{40} \sum_{\mathrm{m}=1}^{12} \sum_{\mathrm{p}=1}^{10} \mathrm{QT}_{\mathrm{i}, \mathrm{j}, \mathrm{m}, \mathrm{p}} \cdot\left(\mathrm{ApB}_{\mathrm{i}, \mathrm{j}, \mathrm{m}, \mathrm{p}}-\mathrm{ApL}_{\mathrm{p}}\right)
$$

Que ao substituir $\left(A p B_{i, j, m, p}-A p L_{p}\right)$ pela equação fator previdenciário, vem:

\section{Equação 6}

$$
\text { Custo Adicional }=\sum_{\mathrm{i}=1}^{10} \sum_{\mathrm{j}=30}^{40} \sum_{\mathrm{m}=1}^{12} \sum_{\mathrm{p}=1}^{10}\left(\mathrm{QT}_{\mathrm{j}} \cdot \frac{\mathrm{QT}_{\mathrm{i}}}{\sum \mathrm{QT}_{\mathrm{i}}} \cdot \frac{\mathrm{QT}_{\mathrm{m}}}{\sum \mathrm{QT}_{\mathrm{m}}} \cdot \frac{\mathrm{QT}_{\mathrm{p}}}{\sum \mathrm{QT}_{\mathrm{p}}} \cdot\left(\frac{\mathrm{ApL}_{\mathrm{p}}}{\frac{\mathrm{Tc}_{\mathrm{j}} \cdot \mathrm{a}}{\mathrm{Es}_{\mathrm{i}}} \cdot\left[1+\left(\frac{\mathrm{Id}_{\mathrm{i}}+\mathrm{Tc}_{\mathrm{j}} \cdot \mathrm{a}}{100}\right)\right]}-\mathrm{ApL}_{\mathrm{p}}\right)\right)
$$

Entretanto, no período em que não há incidência do fator de transição, pode-se mantê-lo na equação custo adicional. Para isso, utiliza-se $n=60$ para os anos em que não há mais a sua aplicação. Por fim, tem-se a equação custo definitiva:

\section{Equação 7}

$$
\text { CUSTO }=\sum_{\mathrm{i}=1}^{10} \sum_{\mathrm{j}=30}^{40} \sum_{\mathrm{m}=1}^{12} \sum_{\mathrm{p}=1}^{10}\left(\mathrm{QT}_{\mathrm{j}} \cdot \frac{\mathrm{QT}_{\mathrm{i}}}{\sum \mathrm{QT}_{\mathrm{i}}} \cdot \frac{\mathrm{QT}_{\mathrm{m}}}{\sum \mathrm{QT}_{\mathrm{m}}} \cdot \frac{\mathrm{QT}_{\mathrm{p}}}{\sum \mathrm{QT} \mathrm{T}_{\mathrm{p}}} \cdot\left(\frac{\mathrm{ApL}_{\mathrm{p}}}{\left(\left(\frac{\mathrm{Tc}_{\mathrm{j}} \cdot \mathrm{a}}{\mathrm{ES}_{\mathrm{i}}} \cdot\left(1+\left(\frac{\mathrm{Id}_{\mathrm{i}}+\mathrm{Tc}_{\mathrm{j}} \cdot \mathrm{a}}{100}\right)\right)\right) \cdot \frac{\mathrm{n}}{60}\right)+\left(\frac{60-\mathrm{n}}{60}\right)}-\mathrm{ApL}_{\mathrm{p}}\right)\right)
$$


Em que: $Q T=$ quantidade de aposentadorias concedidas, dado certo tempo de contribuição $j$, uma idade $i$, um mês $m$, ou uma faixa salarial $p$, apresentadas na Tabela $6 ; A p L=$ faixa salarial $p$ (que corresponde ao valor que o beneficiário atualmente recebe); $T C=$ Tempo de contribuição $; ; / d=I d a d e ~ i ; ~ E s=$ esperança de sobrevida (retirada do IBGE), dada uma idade $i ; n=$ número de meses transcorridos desde a aplicação do fator, na qual, a partir de 2005, foi considerado $n=60$, já que o fator permanece o mesmo; $a=0,31$.

Esta equação definitiva calcula, somente, o custo adicional que o governo teria no mês que deferiu a aposentadoria, dotando-se de diferentes tabelas para os gêneros, com a ressalva de que para as mulheres, o tempo de contribuição começa aos 25 anos $(j=25)$.

Ademais, foram excluídas desses cálculos pessoas que receberam benefícios acima de 10 salários mínimos vigente em cada ano e indivíduos com mais de 80 anos, pois representam menos de $1 \%$ das aposentadorias analisadas. Sobretudo, pessoas com tempo de contribuição não revelado foram retiradas, e aquelas que se aposentaram com 40 ou mais anos foram consideradas como $T c=40$.

Vale ressaltar que há casos em que aposentados receberiam menos do que já recebiam; devido ao fator, hora aplicado, ser maior do que 1 , na qual permite àqueles tardiamente aposentados ganharem um bônus no valor do benefício. Assim, acredita-se que, para os quais o fator era maior que 1 , o segurado não teria a aposentadoria reduzida e, portanto, não haveria gasto adicional para o governo.

Por fim, para aqueles em que a aposentadoria sem o fator ultrapassou o teto previdenciário vigente, supõe-se que teriam seus benefícios reduzidos ao valor do teto. Por sua vez os que já recebiam acima do teto, continuarão a receber a mesma quantia.

\section{Resultados}

A partir do procedimento descrito, obtêm-se a diferença estimada entre os gastos previdenciários das ATCS, com o fator previdenciário em relação aos sem o fator, concedidas de 2000 a 2009.

Estes valores, obtidos da equação custo, além de serem indexados ao índice Nacional de Preços ao Consumidor (INPC) de dezembro de 2010 (a fim de tornálos atualizados), foram multiplicados por 13, número referente à quantidade de salários recebidos por ano, e pelo número de anos desde a concessão da aposentadoria até a morte dos segurados (estimada pela Tabela de Sobrevida do IBGE). 
Tabela 14. Gastos adicionais do governo, considerando-se a inexistência do fator, para ATCs concedidas entre 2000 e 2009 (em reais de dezembro de 2010).

\begin{tabular}{lccc} 
Ano & Gasto Adicional Anual & Gasto Adicional Total* & $\begin{array}{c}\text { Gasto Adicional Total } \\
\text { Anualizado** }\end{array}$ \\
\hline 2000 & 116.196 .336 & 3.836 .844 .421 & 94.271 .361 \\
\hline 2001 & 233.921 .760 & 7.055 .951 .860 & 172.517 .160 \\
\hline 2002 & 568.054 .224 & 16.488 .875 .739 & 402.167 .701 \\
\hline 2003 & 610.917 .631 & 17.498 .504 .456 & 424.720 .982 \\
\hline 2004 & 1.482 .801 .642 & 45.687 .336 .492 & 1.052 .703 .606 \\
\hline 2006 & 1.555 .867 .020 & 48.241 .998 .818 & 1.106 .467 .863 \\
\hline 2007 & 1.906 .958 .573 & 59.453 .516 .687 & 1.357 .386 .226 \\
\hline 2008 & 2.533 .257 .307 & 79.024 .388 .790 & 1.796 .008 .836 \\
\hline Total & 2.717 .480 .859 & 85.539 .293 .308 & 1.935 .278 .129 \\
\hline
\end{tabular}

* Considera-se até o último grupo de aposentados no estudo falecer (37 anos), tendo como referência a tabela de sobrevida do IBGE;

** Gasto Adicional Total dividido pela expectativa de sobrevida do grupo mais jovem.

Fonte: Elaboração dos autores.

Tabela 15. Economia estimada com aplicação do Fator Previdenciário nas ATCs de 2000 a 2009 (em \%).

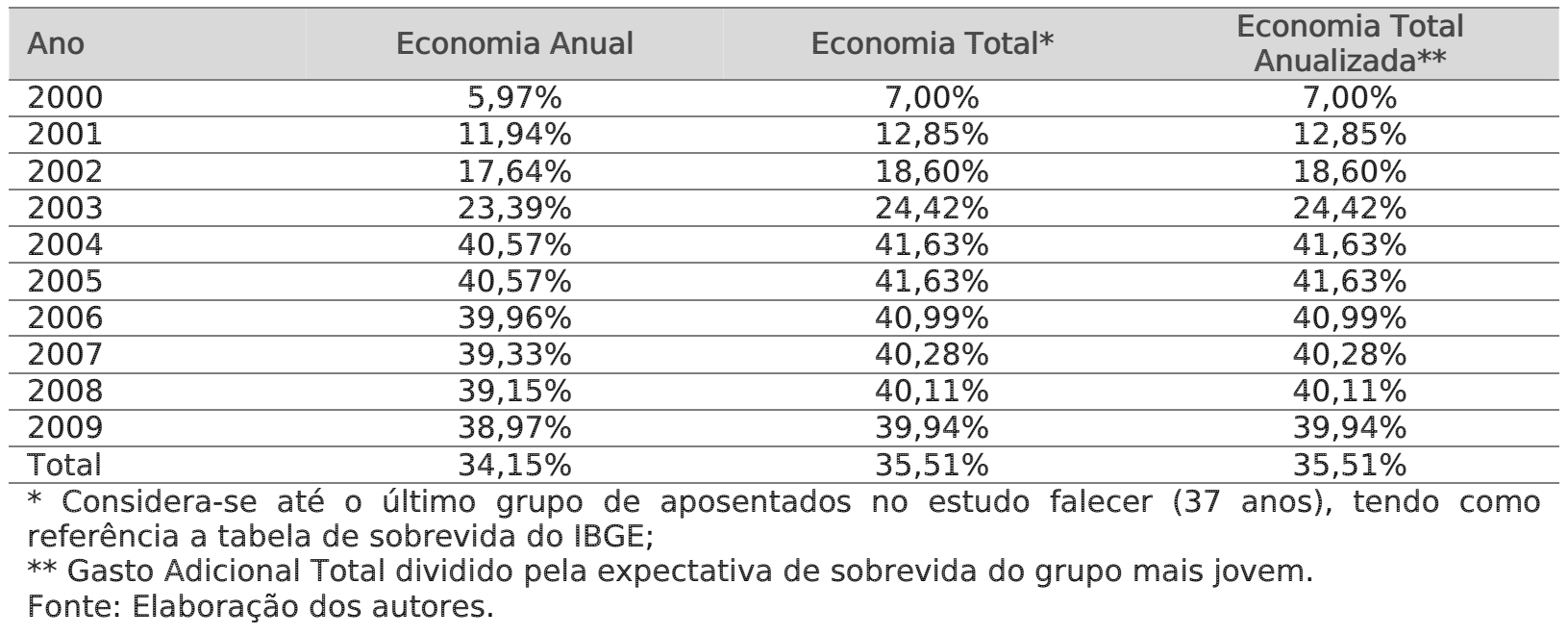

Dessa maneira, alcança-se o escopo do trabalho. Observando-se a Tabela 14, tem-se que o INSS gastaria a mais, anualmente, cerca de $R \$ 14$ bilhões aos que solicitaram a aposentadoria no período 2000-2009.

Esta economia, porém, não considera que os segurados podem falecer antes de alcançarem a expectativa de sobrevida. Ao incluir esta possibilidade de óbito, o governo despenderia cerca de $\mathrm{R} \$ 10$ bilhões anuais, totalizando em quase $\mathrm{R} \$ 450$ bilhões ao final do último ano de vida do grupo de segurados que viveu por mais tempo.

Isso representa uma despesa total de $35,5 \%$, caso o fator não fosse utilizado. Porém, vale ressaltar que os valores e a redução no custo orçamentário foram estimados tendo como base a inflação, enquanto que certas faixas de benefícios 
previdenciários apresentaram reajustes superiores ao índice acumulado do período. Assim, o montante economizado pode se alterar.

\section{Conclusão}

Decorrida a análise empírica contrafactual realizada no trabalho, conclui-se, por meio do resultado final obtido, gastos excedentes no valor de $R \$$ 454.243.224.144 (quatrocentos e cinquenta e quatro bilhões, duzentos e quarenta e três milhões, duzentos e vinte e quatro mil, cento e quarenta e quatro reais) sem o fator, a partir do ano 2000 até a morte dos beneficiados que a requereram no período analisado. Por ano, a economia chega a 10 bilhões de reais, um valor impressivo.

Nota-se também que a economia, em termos percentuais, possui magnitude que não pode ser ignorada. A partir de 2004, último ano do fator de transição, a economia obtida pelo governo se mantém estável na casa dos 40\%, mas com uma pequena tendência de diminuição.

Assim, infere-se que se o fator previdenciário fosse extinto, o governo teria um dispêndio maior, que possivelmente seria intensificado pelo envelhecimento demográfico brasileiro. A partir disso, percebe-se a relevância do mecanismo para a manutenção do sistema previdenciário do país, o qual já apresenta grande déficit orçamentário.

\section{Referências}

Brasil. Constituição da República Federativa da Brasil. Brasília, 1988. Disponível na internet em: http://www.planalto.gov.br/ccivil_03/constituicao/constitui\%C3\%A7ao.htm [Acesso em 17 fev. 2011].

Brasil. Lei 9.876, de 26 de novembro de 1999. Disponível na internet em: http://www.planalto.gov.br/ccivil_03/Leis/L9876.htm [ Acesso em 27 mai. 2010].

Brasil. Medida Provisória 475, de 23 de dezembro de 2009. Disponível na internet em: http://www.planalto.gov.br/ccivil_03/_Ato2007-2010/2009/Mpv/475.htm [ Acesso em 27 mai. 2010].

Brasil. Projeto Lei 3.299, de 2008. Disponível na internet em: http://www.camara.gov.br/sileg/integras/601471.pdf [Acesso em 27 mai. 2010]. 
Carvalho JAM, Garcia RA. O envelhecimento da população brasileira: um enfoque demográfico. Cad Saúde Púb/. 2003, 19(3):725-33. Disponível na internet em: http://www.scielosp.org/pdf/csp/v19n3/15876.pdf [ Acesso em 23 mai. 2010].

Delgado GC, Querino AC, Rangel L, Stivali M. Avaliação de resultados da lei do fator previdenciário (1999-2004). Texto para discussão 1161. Brasília, IPEA, 2006.

Empresa de Tecnologia e Informações da Previdência Social (DATAPREV). Tabela de expectativa de sobrevida. Disponível na internet em: http://www010.dataprev.gov.br/cws/contexto/conrmi/tabES.htm [Acesso em 23 mai. 2010].

Giambiagi F, Afonso LE. Cálculo da alíquota de contribuição previdenciária atuarialmente equilibrada: uma aplicação ao caso brasileiro. Rev Bras Econ. 2009, 63(2):153-79.

Instituto Brasileiro de Geografia e Estatística (IBGE). Indice Nacional de Preços ao Consumidor. Disponível na internet em: http://www.ibge.gov.br/home/estatistica/indicadores/precos/inpc_ipca/defaulti npc.shtm [ Acesso em 29 mai. 2010].

Ministério da Previdência Social. Anuário Estatístico da Previdência Social, 2005. Brasília, 2005. Disponível na internet em: http://www.mps.gov.br/arquivos/office/3_081013-161950-633.pdf [ Acesso em 23 mai. 2010].

Ministério da Previdência Social. Anuário Estatístico da Previdência Social, 2008. Brasília, 2008. Disponível na internet em: http://www.mps.gov.br/arquivos/office/3_091028-191015-957.pdf [ Acesso em 23 mai. 2010].

Ministério da Previdência Social. Boletim Estatístico da Previdência Social, 2009. Brasília, 2009. Disponível na internet em: http://www.previdenciasocial.gov.br/arquivos/compressed/3_100517-175555913.zip [ Acesso em 23 mai. 2010].

Ministério da Previdência Social. Suplemento do Anuário Estatístico da Previdência Social, 2008. Disponível na internet em: http://www.previdenciasocial.gov.br/arquivos/compressed/3_100531-133431508.zip [ Acesso em 23 mai. 2010].

Otta LA. Fator previdenciário é mantido para evitar ampliação de rombo. 0 Estado de São Paulo, São Paulo, 16 jun. 2010. Economia, B1. 